Correction

\title{
Correction: Liu et al. Detection of Human Fall Using Floor Vibration and Multi-Features Semi-Supervised SVM. Sensors $2019,19,3720$
}

\author{
Chengyin Liu ${ }^{1}$, Zhaoshuo Jiang ${ }^{2, *(\mathbb{D}}$, Xiangxiang $\mathrm{Su}^{1}$, Samuel Benzoni ${ }^{2}$ and Alec Maxwell ${ }^{2}$ \\ 1 Department of Civil and Environmental Engineering, Harbin Institute of Technology, \\ Shenzhen 518055, China; chengyin.liu@hit.edu.cn (C.L.); suxiangxiang@stu.hit.edu.cn (X.S.) \\ 2 School of Engineering, San Francisco State University, San Francisco, CA 94132, USA; \\ sbenzoni@mail.sfsu.edu (S.B.); awm@mail.sfsu.edu (A.M.) \\ * Correspondence: zsjiang@sfsu.edu; Tel.: +1-415-338-7741
}

check for updates

Citation: Liu, C.; Jiang, Z.; Su, X.; Benzoni, S.; Maxwell, A. Correction Liu et al. Detection of Human Fall Using Floor Vibration and MultiFeatures Semi-Supervised SVM. Sensors 2019, 19, 3720. Sensors 2021, 21, 3841. https://doi.org/10.3390/ s21113841

Received: 25 January 2021

Accepted: 16 April 2021

Published: 2 June 2021

Publisher's Note: MDPI stays neutral with regard to jurisdictional claims in published maps and institutional affiliations.

Copyright: (C) 2021 by the authors. Licensee MDPI, Basel, Switzerland. This article is an open access article distributed under the terms and conditions of the Creative Commons Attribution (CC BY) license (https:// creativecommons.org/licenses/by/ $4.0 /)$.
The authors wish to add one reference [1] to this paper [2].

On page 1, the original sentences are as follows: Progress toward new methods without cameras has been made through the use of accelerometer sensors mounted on the structure to capture floor vibration for human activities detection [13-15].

Correction to be: Progress toward new methods without cameras has been made through the use of accelerometer sensors mounted on the structure to capture floor vibration for human activities detection [13-16].

The sequential references originally in the paper (i.e., [16-47]) will shift by one (i.e., [17-48]).

The authors apologize for any inconvenience caused and state that the scientific conclusions are unaffected. The original article has been updated.

Conflicts of Interest: The authors declare no conflict of interest.

\section{References}

1. Davis, B.T. Characterization of Human-Induced Vibrations. Ph.D. Dissertation, University of South Carolina, Columbia, SC, USA, 2016. Available online: https:/ / scholarcommons.sc.edu/ etd/3770 (accessed on 25 January 2019).

2. Liu, C.; Jiang, Z.; Su, X.; Benzoni, S.; Maxwell, A. Detection of human fall using floor vibration and multi-features semi-supervised SVM. Sensors 2019, 19, 3720. [CrossRef] 